\section{Benign distal jejunal stricture treated by a partially covered esophageal stent with the use of spiral enteroscopy}

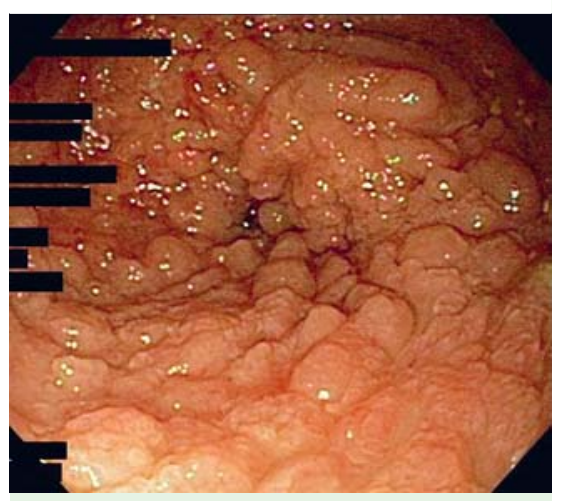

Fig. 1 Distal jejunal stricture with granular, friable mucosa and superficial ulceration in a 73-year-old women with a history of fistulizing Crohn's disease.

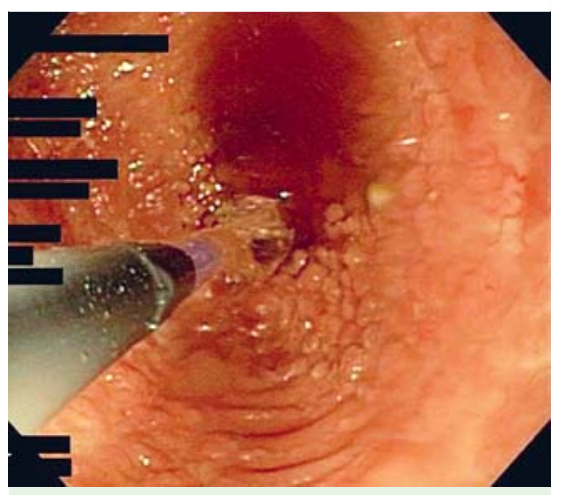

Fig. 2 Balloon dilation with a through-thescope balloon.

Malignant strictures of the proximal to mid small bowel have been successfully managed by deploying enteral stents with the use of an overtube [1,2]. In case reports and published series, stents have been deployed only to the ligament of Treitz and rarely into the proximal jejunum $[3,4]$. We present here the case of a benign stricture in the distal jejunum managed by deploying a partially covered esophageal stent with the use of spiral enteroscopy.

A 73-year-old woman who had a history of fistulizing Crohn's disease presented with recurrent small-bowel obstruction. Peroral spiral enteroscopy identified a tight stricture $1.5 \mathrm{~m}$ beyond the ligament of Treitz ( $\bullet$ Fig. 1). Balloon dilation with a through-the-scope-balloon (CRE Balloon
Dilator; Boston Scientific, Natick, Massachusetts, USA) was performed ( Fig. 2). Despite progressive dilation over 6 weeks, the patient had a further episode of bowel obstruction. Following a discussion of the therapeutic options, the patient declined surgery and elected endoscopic therapy with the insertion of a self-expandable metallic stent (SEMS).

The stricture was identified during peroral spiral enteroscopy. The mucosa proximal to the stricture was erythematous and ulcerated. The injection of contrast revealed that the stricture was $3 \mathrm{~cm}$ in length. Under fluoroscopic guidance, a 0.035-in super-stiff Jagwire (Boston Scientific) was inserted through the stricture into the more distal part of the small bowel. The enteroscope was removed, and the overtube remained in position. An $18 \times 60-\mathrm{mm}$ partially covered self-expandable metallic esophageal stent (Niti-S; Taewoong Medical, Seoul, South Korea) was inserted over the guidewire and deployed across the stricture ( Fig.3a). Unfortunately, the proximal $1 \mathrm{~cm}$ of the stent was deployed within the overtube ( $\bullet$ Fig.3b). The spiral overtube was rotated counterclockwise as it was being withdrawn. The stent was then successfully released from the overtube and deployed in an optimal position, which was confirmed fluoroscopically and endoscopically ( Fig.4). The procedure is shown in $\bullet$ Video 1.

The patient was discharged home on a low roughage diet. She returned for surveillance enteroscopy at 6 weeks. At that time, the stent was removed, and the stricture had markedly decreased. At 6-month follow-up, the patient has had no further episodes of small-bowel obstruction (ه Fig.5).

This case demonstrates the feasibility, efficacy, and safety of using a temporarily placed, partially covered SEMS to manage a deep small-bowel stricture.

\section{Video 1}

Treatment of a benign distal jejunal stricture by a partially covered esophageal stent deployed with the use of spiral enteroscopy.

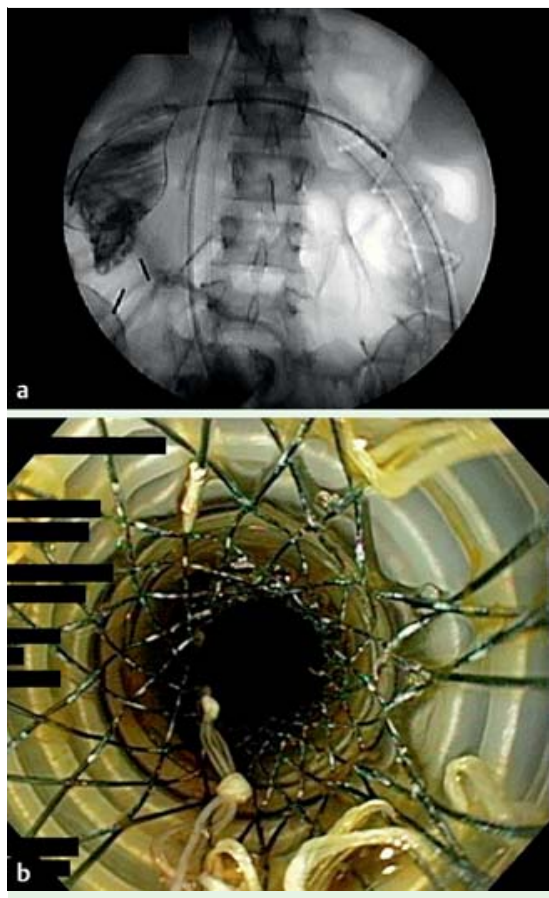

Fig. 3 a Fluoroscopic image of the stent being deployed across the stricture. $\mathbf{b}$ The proximal portion of the stent is lodged within the overtube after deployment.

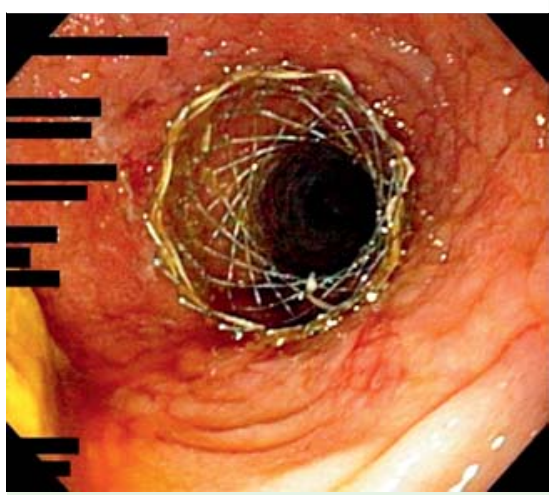

Fig. 4 The stent successfully deployed within the stricture.

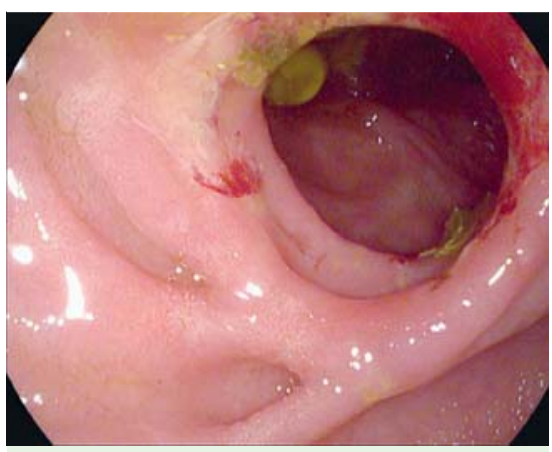

Fig. 5 Endoscopic image obtained during follow-up procedure after stent removal shows increased luminal patency. 


\section{Endoscopy_UCTN_Code_TTT_1AP_2AD}

Competing interests: Mouen A. Khashab is a consultant for Boston Scientific and Olympus America and has received research support from Cook Medical.

\section{Frances Onyimba, Vivek Kumbhari, Alan Tieu, Jennifer Cai, Ahmed Abdegelil, Aditi Reddy, Mouen A. Khashab, Patrick Okolo}

Department of Medicine, Division of Gastroenterology and Hepatology, The Johns Hopkins Medical Institutions, Baltimore, Maryland, USA

\section{References}

1 Kita H, Yamamoto H, Yano T et al. Double balloon endoscopy in two hundred fifty cases for the diagnosis and treatment of small intestinal disorders. Inflammopharmacology $2007 ; 15: 74-77$

2 Samalin E, Assenat E, Bauret $P$ et al. Self-expandable metal stents placed with overtube for the treatment of malignant obstruction of the gastrointestinal tract in 33 consecutive patients. Endoscopy 2007; 39 (Suppl. 01): E101

3 Zhang F, Amateau SK, Khashab MA et al. Midgut stents. Curr Opin Gastroenterol 2012; 28: $451-460$

4 Tharian B, Caddy G, Tham TC. Enteroscopy in small bowel Crohn's disease: a review. World J Gastrointest Endosc 2013; 5: 476 486

\section{Bibliography}

DoI http://dx.doi.org/

10.1055/s-0034-1391334

Endoscopy 2015; 47: E117-E118

(c) Georg Thieme Verlag KG

Stuttgart · New York

ISSN 0013-726X

\section{Corresponding author}

\section{Vivek Kumbhari, MD}

Interventional Endoscopist

Johns Hopkins Hospital

1800 Orleans Street, Suite 2058 B

Baltimore, MD 21205

USA

Fax: 1-443-683-8335

vkumbhari@gmail.com

\section{Correction}

Onyimba F, Kumbhari V, Tieu A et al. Benign distal jejunal stricture treated by a partially covered esophageal stent with the use of spiral enteroscopy. Endoscopy 2015; 47 CTL: E117-E118. DOI: 10.1055/s-0034-1391334. Epub 2015 Mar 11

The author's name Mouen Khashab was corrected to Mouen A. Khashab. 